\title{
RECRYSTALLIZATION CHARACTERISTICS OF OXIDE DISPERSION STRENGTHEIVED NICKEL-BASE ALLOYS
}

\author{
RusselZ K. HotzLer * \\ Thomas K. Glasgow + \\ *Queensborough Cormunity College \\ +NASA-Lewis Research Center
}

Electron microscopy was employed to study the process of recrystallization in two oxide dispersion strengthened (ODS) mechanically alloyed nickel-base alloys, MA 754 and MA 6000E.

MA 754 contained both fine uniformly dispersed particles and coarser oxides alligned along the working direction. Hot rolled MA 754 had a grain size of $0.5 \mu \mathrm{m}$ and high dislocation densities. After partial primary recrystallization, the fine grains transform to large elongated grains via secondary for abnoxmal) grain growth.

Extruded and rolled MA 6000E contained equiaxed grains of $0.2 \mu \mathrm{m}$ dia. Primary recrystallization occurring during working climinated virtually all dislocations. Conversion from fine to coarse grains was triggered by gamma prime ( $\left.\gamma^{\prime}\right)$ dissolution; this was also a process of secondary or abnormat grain growth.

Comparisons were made to conventional and oxide dispersion strengthened nickel-base alloys. 


\section{INTRODUCTION}

The formation of large elongated grains in oxide dispersion strengthened (ODS) alloys has long been recognized as a crucial step in the development of optimum high temperature properties. (1) However, the mechanisms by which these grain structures formed were not well understood. Further, it was observed that the transformations were sensitive to both prior thermal and mechanical history and varied greatly in characleristics depending on alloy composition. $(2,3)$ For example those alloys known to precipitate large $(>50 \%)$ quantities of $\gamma$ "exhibited rapid coarse grain transformations and only at temperatures above their $\gamma^{\prime}$ solvus. $(4,5)$ Alloys containing little or no $\gamma^{\prime}$ on the other hand, exhibited much slower transformations and showed evidence of large grain formation over broader time-temperature spectrums. $(6,7)$ In the present study, an attempt was made to characterize the large grain transformations common to 2 ODS nickel-base alloys, MA 754 (8) and MA $6000 \mathrm{E}$ (9). These recently developed alloys contain Y A1 03 type dispersoids and are produced by mechanical alloying. MA 754 essentially represents a nickel-chromium based solid solution strengthened only by the presence of a dispersoid while the highiy alloyed MA $6000 \mathrm{E}$ is strengthened by both a dispersoid and the precipitation of approximately 50\% $\gamma^{\prime}$. Attempts have been made to elucidate the role of grain size, thermomechanical working, oxide dispersion and $\gamma^{\prime}$ precipitation as related to the large grain transformation mechanisms.

\section{PROCEDURE}

Both the MA 6000E and the MA 754 employed in this investigation were produced by the International Nickel Company using mechanical alloying techniques. MA $6000 \mathrm{E}$ bars were fabricated from attrition milled powder which was consolidated by an $8: 1$ extrusion at $1010^{\circ} \mathrm{C}$ and subsequently hot-rolled $50 \%$ (10420 $\mathrm{C}$ using a 2 pass sequence. The MA 754 bars were also fabricated from attrition milled powder, however the specific extrusion and hot rolling parameters were proprietary. Chemical compositions for both alloys are provided in Table 1.

TABLE I - CHEMICAL COMPOSITIONS (Wt.\%)

$\begin{array}{lllllllllllllll}\text { Alloy } & \text { Ni } & \text { Cr } & \text { Ti } & \text { AI } & \text { Y } & 0 & \text { N } & \text { C } & \text { Fe } & \text { Mo } & \text { W } & \text { Ta } & \text { B } & \text { Zr } \\ \text { MA 754 } & \text { Bal } & 20.2 & 0.5 & 0.3 & 0.52 & 0.42 & 0.12 & 0.06 & 1.0 & - & - & - & \text { N.D. } & \text { N.D. } \\ \text { MA 6000E } & \text { BaI } & 14.0 & 2.3 & 4.6 & 0.74 & 0.57 & 0.15 & 0.07 & 0.2 & 2.0 & 4.0 & 2.1 & 0.03 & 0.07\end{array}$


Al1 thermal treatments were carried out in argon atmospheres including gradient annealing which was performed in a stationary temperature gradient of $\simeq 30^{\circ} \mathrm{C} / \mathrm{cm}$. Reported temperatures were controlled to within $\pm 2^{\circ} \mathrm{C}$.

The $\gamma^{\prime}$ and coarse oxide dispersions were examined using platinum shadowed parlodion surface replicas while the fine grained structures were studied by means of transmission electron microscopy. Both grain and particle size determinations were obtained from micrographs recorded on plates. Lineal intercept methods were employed to determine grain sizes with a 1000 grain sample used for each measurement and the resulting sizes reported as average lineal intercept values-' $\bar{L}$ '. Volume fractions were determined using point counting techniques.

\section{RESULTS}

Transmission electron microscopy was used to characterize as-received extruded and hot-rolled MA 6000E and MA 754 microstructures. MA $6000 \mathrm{E}$ exhibits an extremely fine equiaxed structure (Figure 1 a ) having an average grain size of $\simeq 0.2 \mathrm{fm}(\overline{\mathrm{I}})$. Similar grain morphologies were recorded for both transverse and longitudinal sections. Primary recrystallization was judged to have occurred dynamically during, or immediately following, the hot-working operations thus accounting for the extremely low dislocation density. The dispersoid appeared exceedingly fine and uniform with an average volumetric particle size of $\simeq 240 \AA$ and showed no evidence of any directional alignment (stringers). $\gamma^{\prime}$ particles appeared blocky and surface replicas revealed that their sizes were comparable to those of the matrix grains $(\approx 0.2 \mu \mathrm{m})$, although an extremely fine $\gamma^{\prime}$ dispersion was also observed.

MA 754 in the extruded and hot-rolled condition (Figure $1 \mathrm{~b}$ ) also exhibited an extremely fine grain morphology; however, in this case the average grain size appeared as $\simeq 0.6 \mathrm{~mm}$ in the longitudinal section and $\simeq 0.4 \mu \mathrm{m}$ in the transverse section thereby indicating a slightly oblong grain shape. In contrast to the MA $6000 \mathrm{E}$, the hot-rolled MA 754 microstructures revealed extremely high dislocation densities and a duplex dispersoid consisting of a uniform fine particle distribution (similar to that found in the MA 6000E) and a much coarser oxide $(0.5-4 \mu \mathrm{m})$ strongly oriented along the primary working direction. Figure 2 illustrates the macrostructures developed in longitudinal bars of MA 754 and MA 6000E following 1 hour exposure to a stationary thermal gradient. The large grain 

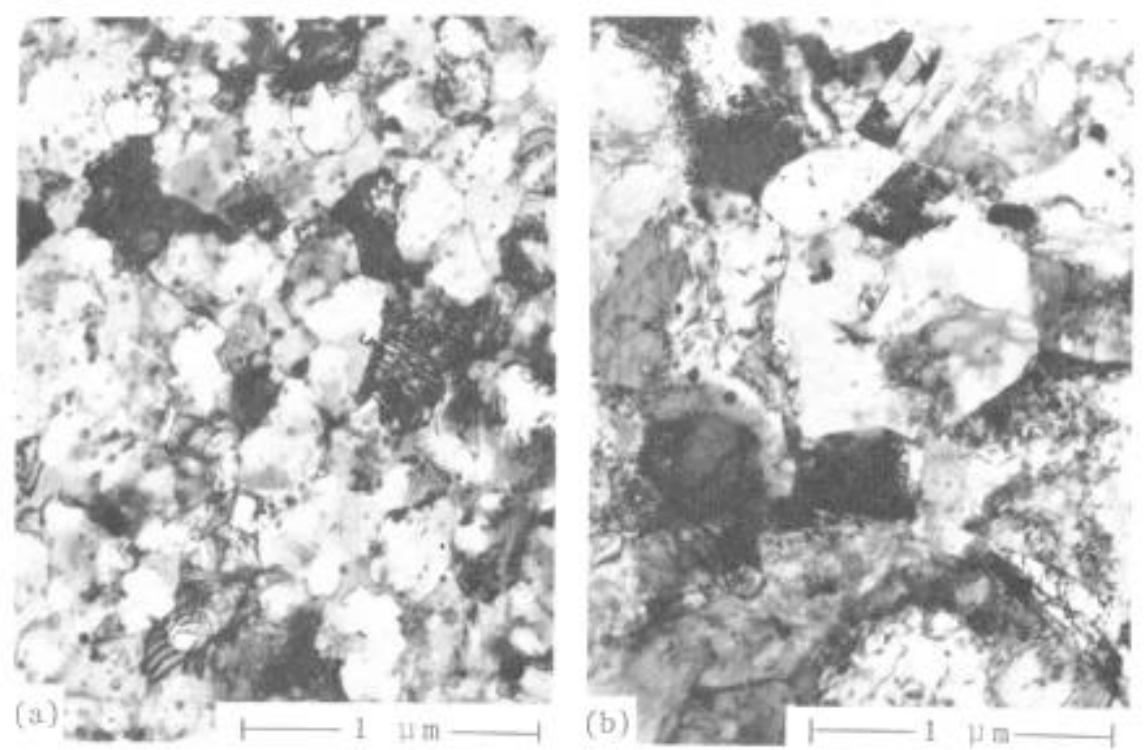

Figure 1 - (a) Transmission micrograph of MA $6000 \mathrm{E}$ following hot-rolling at $1042^{\circ} \mathrm{C}$. (b) Transmission micrograph of MA 754 following hot-rolling.

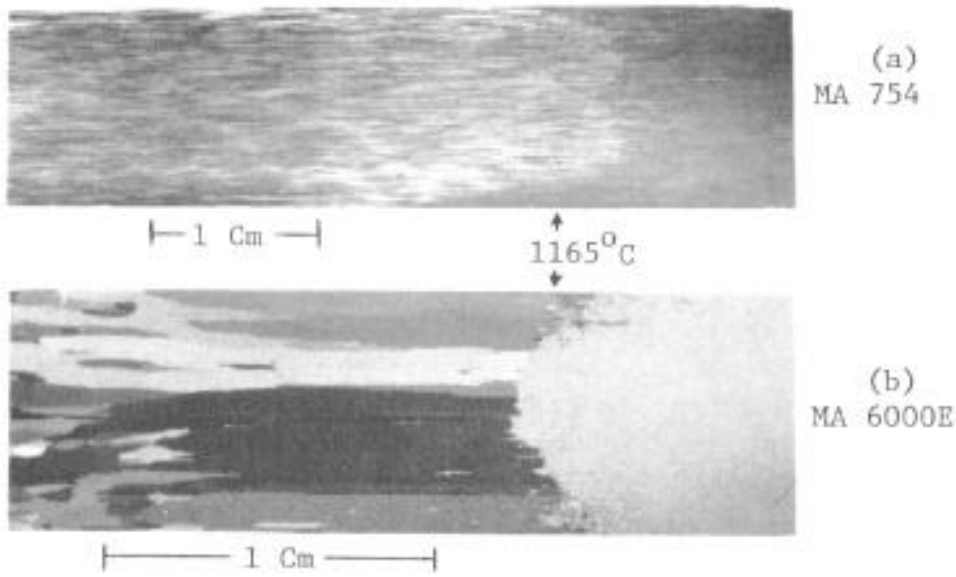

Figure 2 - (a \& b) Gradient bar macrostructures of MA 754 and MA 6000E following one hour exposure to a stationary thermal gradient - longitudinal sections of rolled product. 
formation observed in the MA $6000 \mathrm{E}$ was found to occur at a11 temperatures above $1165^{\circ} \mathrm{C} \pm 3^{\circ} \mathrm{C}$ as indicated by the position of the interface on the gradient bar. MA 754 displayed a less defined interface effect and much narrower elongated grains. Upon continued gradient exposure, the position of the original $1165^{\circ} \mathrm{C}$ interface remained unchanged in the MA $6000 \mathrm{E}$ and no further transformation was detected regardless of exposure time. In contrast, however, the MA 754 exhibited continued large grain formation down to temperatures of $\simeq 1050^{\circ} \mathrm{C}$ after 200 hours.

\section{Secondary Recrystallization of MA $6000 \mathrm{E}$}

As prinary recrystallization is essentially completed by a dynamic mechanism following extrusion and hot-rolling, the large grains which appear upon annealing above $1165^{\circ} \mathrm{C}$ must result from a secondary recrystallization (SRx) process. (10) To help elucidate the factors controlling this transformation, surface replicas were obtained from the interface regions of the gradient bar. Figure 3 illustrates the $\gamma^{\prime}$ morphologies revealed by these replicas. It appears that the areas which transformed to a coarse columnar grained structure had been heated to temperatures above the $\gamma^{\prime}$ solvus as the $\gamma^{\prime}$ in these regions has reprecipitated (upon cooling) into a much finer morphology than that exhibited by the hot-rolled structure. This structure is represented by the coarser, blocky $\gamma^{\prime}$ still prevailing in the untransformed or fine grained regions that wcre not heated above the solvus. Thus, the observed SRx transformation appears to be triggered by $\gamma^{\prime}$ dissolution and the critical reaction temperature controlled by the solvus.

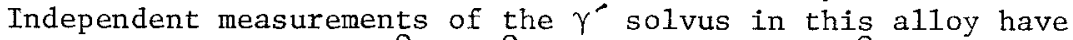
established it as $1175^{\circ} \mathrm{C} \pm 5^{\circ}$ using DTA and $1160^{\circ} \mathrm{C}$ using metallographic techniques. (2) The transmission micrograph shown in Figure 4 (a) illustrates the microstructure common to those areas which have experienced SRx. The prescnce of cuboidal $\gamma^{\prime}$ particles is quite evident as is the uniformity of the dispersoid. X-ray diffraction of extracted dispersoids revealed the presence of mixed $\mathrm{YAlO}_{3}$ - type oxides with nitrides and carbides $(\mathrm{Ti}(\mathrm{C}, \mathrm{N})$ ) appearing as small irregular particles having average sizes between 0.1 and $0.5 \mu \mathrm{m}$. Occasional $1 \mu \mathrm{m}$ particles were observed; however, as they are randomly distributed, they only play a minor role in determining the resulting grain shape. This appeared to be primarily controlled by the thermal gradient as it was found that columnar grains could be grown transverse to the primary working directions by proper application of a thermal gradient. 


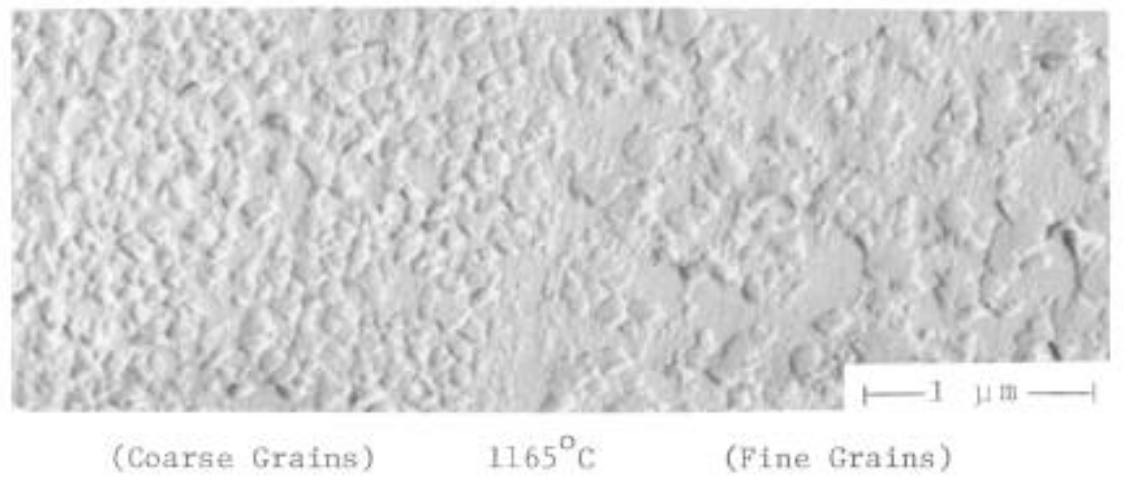

Figure 3 - Surface replica illustrating the $\gamma^{\prime}$ morphology common to the columar grain - fine grain interface after one hour in a steep thermal gradient. Interface temperature $-1165^{\circ} \mathrm{C}$.
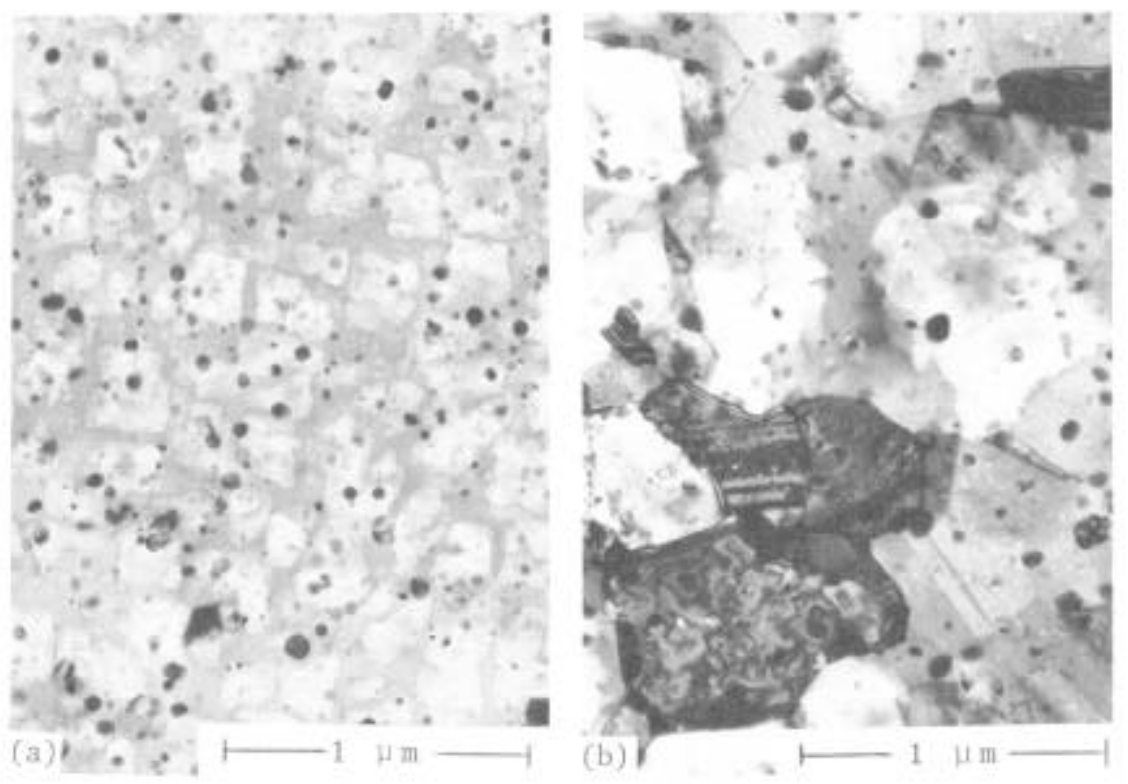

Pigure 4 - (a) Transmission micrograph illustrating the substructure of MA $6000 \mathrm{E}$ following one hour at $1200^{\circ} \mathrm{C}$ $(\mathrm{AC})$.

(b) Transmission micrograph of hot-rolled MA $6000 \mathrm{E}$ following one hour at $1130^{\circ} \mathrm{C} . \quad(\overline{\mathrm{L}}=0.42 \mu \mathrm{m})$. 
TEM conducted on hot-rolled product annealed below the $1165^{\circ} \mathrm{C}$ transformation temperature established that the fine grained structure exhibited normal grain growth behavior at a11 temperatures above $1000^{\circ} \mathrm{C}$. Evidence is provided by the transmission micrograph shown in Figure 4 (b) for a sample annealed one hour at $1130^{\circ} \mathrm{C}$. The average grain size in this sample was measured as $0.42 \mu \mathrm{m}(\overline{\mathrm{L}})$. Analysis of the grain growth data obtaincd revealed that standard ' $t^{\mathrm{n}}$ ' kinetics were operative $(\mathrm{n}=\approx 0.2)$. No evidence of grain boundary dispersoid pinning was observed until the average grain size approached the $0.5 \mu \mathrm{m}$ range. Samples whose grain size increased to $0.5 \mu \mathrm{m}$ or greater during annealing below $1165^{\circ} \mathrm{C}$, no longer exhibited SRx when subsequent1y heated above $1165^{\circ} \mathrm{C}$. (11)

\section{Secondary Recrystallization of MA 754}

"'he high dislocation density and the partially recrystallized equiaxed grain shape common to hot-rolled MA 754 indicates that both deformation and primary recrystallization were occurring simultaneously. Upon exposure to elevated temperatures this deformed fine grain structure was observed to transform to large columnar grains (Figure 2 a ). Their shape was influenced by the coarse oxide which severely restricted lateral grain growth. The transmission micrograph in Figure 5 illustrates the interface between fine grained hotrolled structure and a transformed columnar grain region. This structure was observed in hot-rolled product following a one hour isothermal anneal at $1170^{\circ} \mathrm{C}$. Because very few large grains replaced numerous relatively stable fine grains in a discontinuous manner, the transformation was determined to be one of secondary grain growth. The fine grained structure evident in Figure 5 showed an increase in grain size during annealing $(0.4 \rightarrow 0.56 \mu \mathrm{m} \overline{\mathrm{L}})$; however, this did not appear to restrict the transformation once initiated. Also, it can be noted that significant dislocation densities were still evident within the remaining fine grains despite the observed growth. Strain compliance at the advancing interface appears responsible for generation of the micro-twinned structure common to the SRx material. 


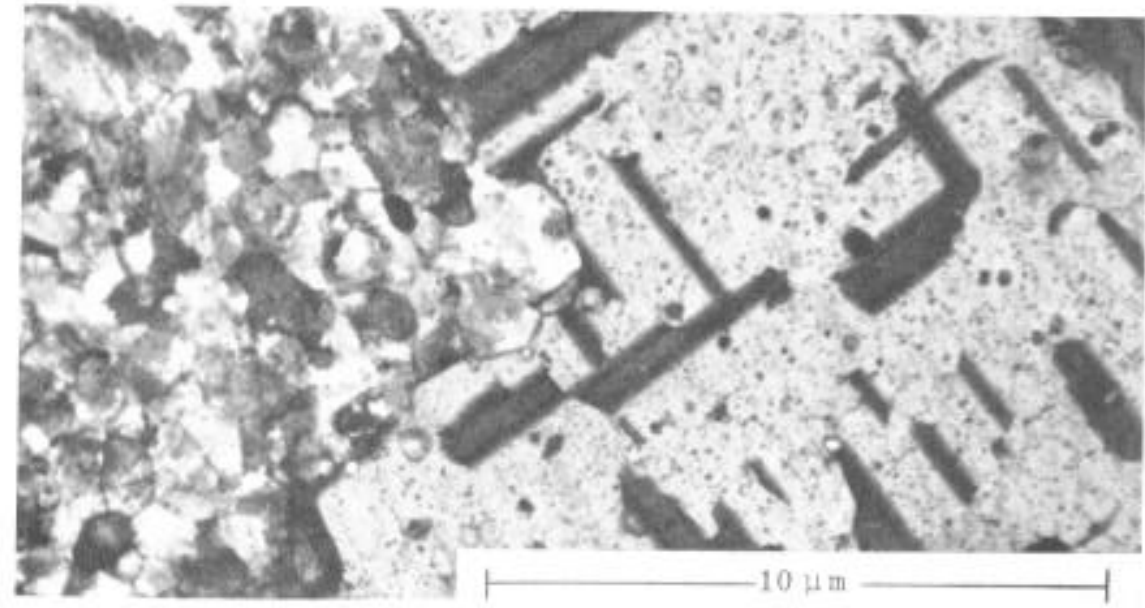

Figure 5 - Transmission micrograph of MA 754 illustrating the interface region between fine grained hot-rolled structure and a secondary recrystallized region.

\section{DISCUSSION}

The SRx behavior of MA $6000 \mathrm{E}$ and MA 754 has been compared with that previously reported for other Ni-base alloys both with and without oxide dispersions. The results can be summarized by the illustration below.

\section{SECONDARY RECRYSTALLIZATION BEHAVIOR OF NICKE1-BASE ALLOYS}

SRX RESPONSE DEPENDENT SOLELY UPON THERMOMECHANICAL. HISTORY

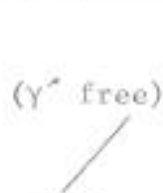

TD $\mathrm{Ni}$

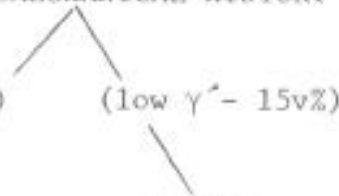

MA 753
DS \& TD NiCr

MA 754
SRX RESPONSE INITIATED BY $\gamma^{\prime}$ DISSOLUTION

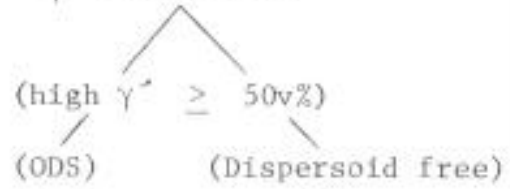

MA $6000 \mathrm{E}$ René 95

WAZ-D RSR Supera11oys 
MA 754 ( $\gamma^{\prime}$ free) exhibits an SRx response which is entirely dependent upon the material's prior thermomechanical history and thus shares the behavior patterns observed for TD Ni, (6) DS and TD Ni Cr. (7) MA 753, (1) which contains small additions of titanium and aluminum, and develops about 15\% $\gamma^{\wedge}$, also exhibits an SRx response which is dependent upon the alloy's prior thermomechanical history. In essence these materials do not adhere to one identifiable transformation temperature, but instead, exhibit a range of temperatures over which SRX occurs depending upon processing. Thus it appears that their $\mathrm{SRx}$ response is dependent purely upon the more classic grain growth mechanisms involving dislocation and grain boundary energy considerations.

In contrast, the high $\gamma^{-}(\geq 50 \mathrm{v} \%)$ alloys which exhibit SRx transformations all appear to have several common characteristics. The most important of which is that their SRx response is initiated or triggered by dissolution of $\gamma^{\prime}$ and therefore, the $\gamma^{\prime}$ solvus represents a critical transformation temperature. This applies to both. the conventional superalloys 713C, (5) René 95 (12) and RSR superalloys (13) as wel1 as the ODS alloys MA 6000E, (11) IN (MA) - 738 $(14,15)$ and WAZ-D. (4) The high $\gamma^{\prime}$ ODS alloys apparently share several other common characteristics including the SRx limiting processes by which thermal exposures below the SRx transformation temperature and/or low heating rates can eliminate the alloy's SRx response. As established by the work on MA 6000E, this effect results from a stabilization of the fine grained structure by both grain growth and the pinning of grain boundaries by coarse dispersoids.

This work was performed at the NASA-Lewis Research Center.

\section{REFERENCES}

1. Cairns, R. I.: Met. Trans., 1974, Volume 5, pp. 1677-1684.

2. Merrick, H. F.: Curwick, L. R. and Kim, Y. G.: Development of Oxide Dispersion Strengthened Turbine Blade Alloy By Mechanical Alloying, NASA CR-135150, 1977.

3. Cairns, R. L.: Curwick, L. R. and Benjamin, J. S.: Met. Trans., 1975, Volume 6A, pp. 179-188.

4. Glasgow, T. K.: Superalloys, Metallurgy and Manufacture, 1976, Claitor's Pub., pp. 385-394. 
5. Miner, R. V.: Study of a Columnar Grain Structure Produced in a Superalloy by Gradient-Annealing Prealloyed Powder Extrusions, NASA TM X-2545, 1972.

6. Petrovic, J. J. and Ebert, L. J.: Met. Trans., 1972, Volume 3, pp. 1131-1136.

7. Kane, R. D. and Ebert, L. J.: Met. Trans., 1975, Volume 6A, pp. 1465-1467.

8. Huntington Alloys, Inconel - MA 754, Specification Data.

9. Kim, Y. G. and Merrick, H. F.: Characterization of an Oxide Dispersion Strengthened Supera11oy, MA 6000E, For Turbine Blade Application, NASA CR-159493, 1979.

10. Hillert, M.: Acta Metallurgica, 1965, Volume 13, pp. 227-238.

11. Hotzler, R. K. and Glasgow, T. K. To be published.

12. Menon, M. N. and Gurney, F. J.: Met. Trans., 1976, Volume 7A pp. 731-743.

13. Bordeau, R. G. and Moore, J. B.: Rapid Solidification Processing, 1978, Claitors Pub., pp. 334-346.

14. Gessinger, G. H.: Met. Trans., 1976, Volume 7A, PP. 12011209.

15. Gessinger, G. H.: Planseeberichte fur Pulvermetallurgie, 1976, Volume 24, pp. 32-41. 